\title{
Microstructural Analysis of Boehmite Nanoparticles Prepared by Rapid Hydrolysis of Aluminum Sec-butoxide
}

\author{
Goran Štefanić* and Svetozar Musić \\ Division of Materials Chemistry, Ruđer Bošković Institute, P.O. Box 180, HR-10002 Zagreb, Croatia \\ RECEIVED MARCH 21, 2011; REVISED MAY 2, 2011; ACCEPTED MAY 5, 2011

\begin{abstract}
Microstructural properties of six samples, prepared by rapid hydrolysis of aluminum secbutoxide, were investigated at RT using field emission scanning electron microscopy (FE SEM), X-ray powder diffraction (XRD) and Fourier transform infrared (FT-IR) spectrometry. The results of structural analysis show that, regardless of a significant difference in the processing parameters $(\mathrm{pH}$, temperature, time of synthesis), all products contain boehmite as the only crystal phase present. The results of FE-SEM analysis indicate a significant difference in the morphology of obtained boehmites (plates, needles, granules). The results of line-broadening analysis of powder diffraction patterns (Le Bail method - program GSAS) indicate the presence of very small anisotropic crystal domains (around 1.5 to $7 \mathrm{~nm}$ in the direction 010; around 3 to $16 \mathrm{~nm}$ in the direction perpendicular to 010). In all cases the parameters that contribute to the strain broadening of diffraction lines decrease to nearly zero, which suggests that the obtained boehmites are almost strain-free. (doi: 10.5562/cca1884)
\end{abstract}

Keywords: microstructure, powder diffraction, electron microscopy, sol-gel growth, oxides

\section{INTRODUCTION}

Boehmite $(\gamma-\mathrm{AlOOH})$ is a major mineral in many types of bauxite which are used as ore in the production of aluminium. ${ }^{1}$ On the other hand, synthetic boehmites are utilized as precursors in the production of various Al-oxide ceramics (membranes, catalysts, ceramic fibers, thin film coatings, etc.). Three synthesis routes were utilized in the synthesis of boehmite: precipitation from inorganic Al-salts in aqueous media, ${ }^{2-5}$ hydrolysis of Al-alkoxides at different $\mathrm{pH},{ }^{6-8}$ and thermal decomposition of gibbsite $\left(\gamma-\mathrm{Al}(\mathrm{OH})_{3}\right) .^{9-11}$ Generally, synthetic boehmites are not easy to characterize due to variations in their crystallinity, particle size and the presence of an amorphous fraction or other Al-oxide phases. The name pseudoboehmite was introduced in reference literature $^{1}$ to describe poor crystalline $\gamma-\mathrm{AlOOH}$, although the criterion for this name is not defined. Crystallographic studies ${ }^{12-14}$ indicate that there is no structural difference between pseudoboehmite and boehmite.

Many researchers investigated the conditions of boehmite formation by slow-hydrolysis of Al-oxides. In the present work we have focused on the synthesis of nanosize boehmite particles using rapid hydrolysis of Al-sec-butoxide and the influence of experimental conditions on the properties of the particles synthesized.

\section{EXPERIMENTAL}

Rapid hydrolysis of aluminum sec-butoxide (Fluka) was used to prepare six samples of Al-oxides (B1 to B6). Preparation conditions are given in Table 1. All the chemicals used were of analytical grade. Structural and microstructural changes in the obtained products were investigated at RT using Fourier transform infrared (FT-IR) spectroscopy, field emission scanning electron microscopy (FE SEM) and X-ray powder diffraction (XRD).

FT-IR spectra were recorded at RT using a PerkinElmer spectrometer, model 2000. The FT-IR spectrometer was coupled with a personal computer and operated with the IRDM (IR Data Manager) program. The specimens were pressed into pellets using spectroscopically pure $\mathrm{KBr}$ as a matrix.

FE SEM analysis of uncoated samples was made using the field emission scanning electron microscope JSM-7000F (JEOL).

XRD measurements were performed using a Philips counter diffractometer MPD1880 with monochromatized $\mathrm{Cu} K \alpha$ radiation (graphite monochromator).

The volume-averaged domain size $\left(D_{\mathrm{V}}\right)$ and the upper limits of micro-strain $(e)$ of the nanosized boehmites were estimated from the results of Le Bail refine-

\footnotetext{
* Author to whom correspondence should be addressed. (E-mail: stefanic@rudjer.irb.hr)
} 
Table 1. Experimental conditions for the preparation of boehmite nanoparticles

\begin{tabular}{|c|c|c|c|c|}
\hline Sample & Al-sec-butoxide / $\mathrm{mL}$ & $\mathrm{H}_{2} \mathrm{O} / \mathrm{mL}$ & TMAH / mL & Procedure \\
\hline B1 & 20 & 179 & - & $\begin{array}{l}1 \mathrm{ml} \text { of conc. acetic acid was dissolved into } 179 \mathrm{~mL} \text { of hot } \mathrm{H}_{2} \mathrm{O} \\
\left(\approx 95^{\circ} \mathrm{C}\right), \text { then vigorously mixed with } 20 \mathrm{~mL} \mathrm{Al} \text {-sec-butoxide. } \\
\mathrm{pH} \approx 3.7 \text {. Autoclaved at } 90^{\circ} \mathrm{C} \text { for } 3 \text { days. }\end{array}$ \\
\hline B2 & 20 & 179.5 & - & $\begin{array}{c}0.5 \mathrm{ml} \text { of conc. acetic acid was dissolved into } 179.5 \mathrm{~mL} \text { of hot } \mathrm{H}_{2} \mathrm{O} \\
\left(\approx 95^{\circ} \mathrm{C}\right), \text { then vigorously mixed with } 20 \mathrm{ml} \text { Al-sec-butoxide. } \\
\mathrm{pH} \approx 4.1 \text {. Autoclaved at } 90^{\circ} \mathrm{C} \text { for } 3 \text { days. }\end{array}$ \\
\hline B3 & 40 & 40 & - & $\begin{array}{l}\text { Al-sec-butoxide and } \mathrm{H}_{2} \mathrm{O} \text { were vigorously mixed. The reaction is } \\
\text { very exothermic. Thixotropic gel is formed. } \mathrm{pH} \approx 6.0 \text {. }\end{array}$ \\
\hline B4 & 30 & 210 & 60 & $\begin{array}{l}\text { Al-sec-butoxide and aqueous solution of TMAH were vigorously } \\
\text { mixed, then autoclaved at } 90^{\circ} \mathrm{C} \text { for } 3 \text { days. } \mathrm{pH} \approx 13.5 \text {. }\end{array}$ \\
\hline B5 & 30 & 210 & 60 & $\begin{array}{l}\text { Al-sec-butoxide and aqueous solution of TMAH were vigorously } \\
\text { mixed. The suspension was filtrated and clear solution was auto- } \\
\text { claved at } 120^{\circ} \mathrm{C} \text { for } 2 \text { days. } \mathrm{pH} \approx 13.5 .\end{array}$ \\
\hline B6 & 30 & 210 & 60 & $\begin{array}{l}\text { Al-sec-butoxide and aqueous solution of TMAH were vigorously } \\
\text { mixed. The suspension was filtrated and clear solution was auto- } \\
\text { claved at } 120^{\circ} \mathrm{C} \text { for } 4 \text { days. } \mathrm{pH} \approx 13.5 \text {. }\end{array}$ \\
\hline
\end{tabular}

Al-sec-butoxide $=\mathrm{Al}\left[\mathrm{O}\left(\mathrm{CH}_{3}\right) \mathrm{CHC}_{2} \mathrm{H}_{5}\right]_{3}$.

$\mathrm{TMAH}=$ tetramethylammonium hydroxide $\mathrm{w}=25 \%$, aq. solution (electronic grade; $99.9999 \%$ ).

ments ${ }^{15}$ (program GSAS ${ }^{16}$ with graphical user interface EXPGUI ${ }^{17}$ ) following the procedure proposed in the Size/Strain Round Robin. ${ }^{18}$ In the refinement we used a modified pseudo-Voigt function defined by Thompson, Cox and Hastings. ${ }^{19}$ The size and strain contribution to the line broadening can be given by the following equation:

$$
\begin{gathered}
\beta_{\mathrm{S}}=\lambda /\left(D_{\mathrm{V}} \cos \theta\right) \\
\beta_{\mathrm{D}}=4 e \tan \theta
\end{gathered}
$$

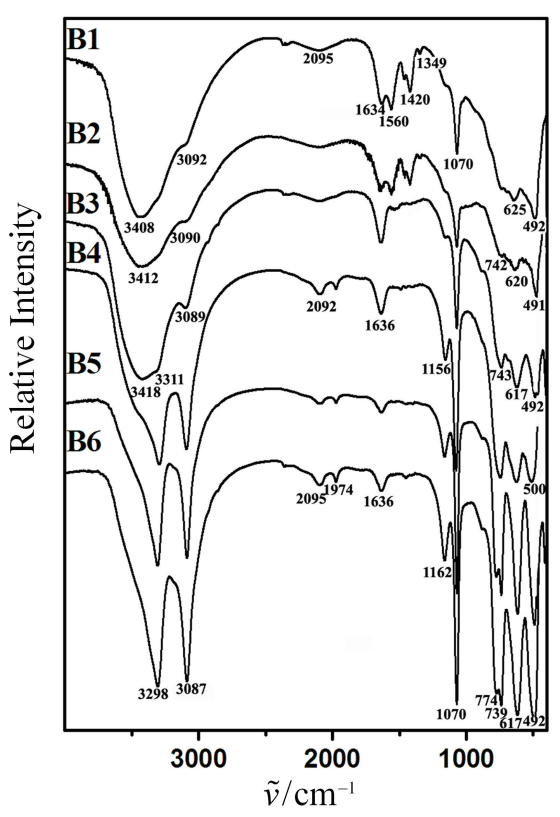

Figure 1. FT-IR spectra of six samples of Al-oxides (B1 to B6) prepared using rapid hydrolysis of aluminum sec-butoxide (Table 1). where $\lambda$ is the wavelength, $D_{\mathrm{V}}$ is the volume-averaged domain size, $i$ represents the upper limits of strain, while $\beta_{\mathrm{S}}$ and $\beta_{\mathrm{D}}$ represent the integral breadths of the Voigt function resulting from size and strain contribution, respectively. In order to obtain pure physically broadened profile parameters, used in the calculation of $\beta_{\mathrm{S}}$ and $\beta_{\mathrm{D}}$ values, the obtained values of refined parameters for samples were corrected by the corresponding values obtained for silicon (Koch-Light Lab. Ltd), used as a standard for the approximation of instrumental profile. The results of the line broadening analysis are summarized in Table 2.

\section{RESULTS AND DISCUSSION}

FT-IR spectra of all samples (Figure 1) contain the bands at approximately 3300, 3090, 1160, 1070, 775, 735,615 , and $490 \mathrm{~cm}^{-1}$, typical of boehmite. ${ }^{20}$ Beside the bands typical of boehmite all spectra contain very broad bands resulting from the vibration of adsorbed water molecules. Samples B1 and B2 also contain bands at 1560,1420 and $1349 \mathrm{~cm}^{-1}$, which indicate the presence of an acetate group ${ }^{21}$ that remained from the acetic acid used in the preparation of the sample (Table 1).

Table 2. Calculated values of $\beta_{\mathrm{S}}$ (degrees $2 \Theta \times 100$ ) and $D_{\mathrm{V}}$ $(\AA)$ in the directions parallel and perpendicular to the axis 010

\begin{tabular}{lccccc}
\hline & $\mathrm{B} 1$ & $\mathrm{~B} 2$ & $\mathrm{~B} 3$ & $\mathrm{~B} 4$ & $\mathrm{~B} 6$ \\
\cline { 2 - 6 }$\beta_{\mathrm{S}}\left(\varphi=0^{\circ}\right)$ & $1163(21)$ & $913(14)$ & $663(12)$ & $272(7)$ & $223(7)$ \\
$\beta_{\mathrm{S}}\left(\varphi=90^{\circ}\right)$ & $462(9)$ & $485(7)$ & $443(7)$ & $117(6)$ & $101(6)$ \\
$D_{\mathrm{V}}\left(\varphi=0^{\circ}\right)$ & $14.1(3)$ & $17.9(3)$ & $24.6(5)$ & $60(2)$ & $73(2)$ \\
$D_{\mathrm{V}}\left(\varphi=90^{\circ}\right)$ & $35.3(8)$ & $33.7(5)$ & $36.8(6)$ & $139(8)$ & $161(10)$ \\
\hline
\end{tabular}


FE-SEM micrographs of samples B1 and B2, obtained at low $\mathrm{pH}$, contain a conglomerate of particles of
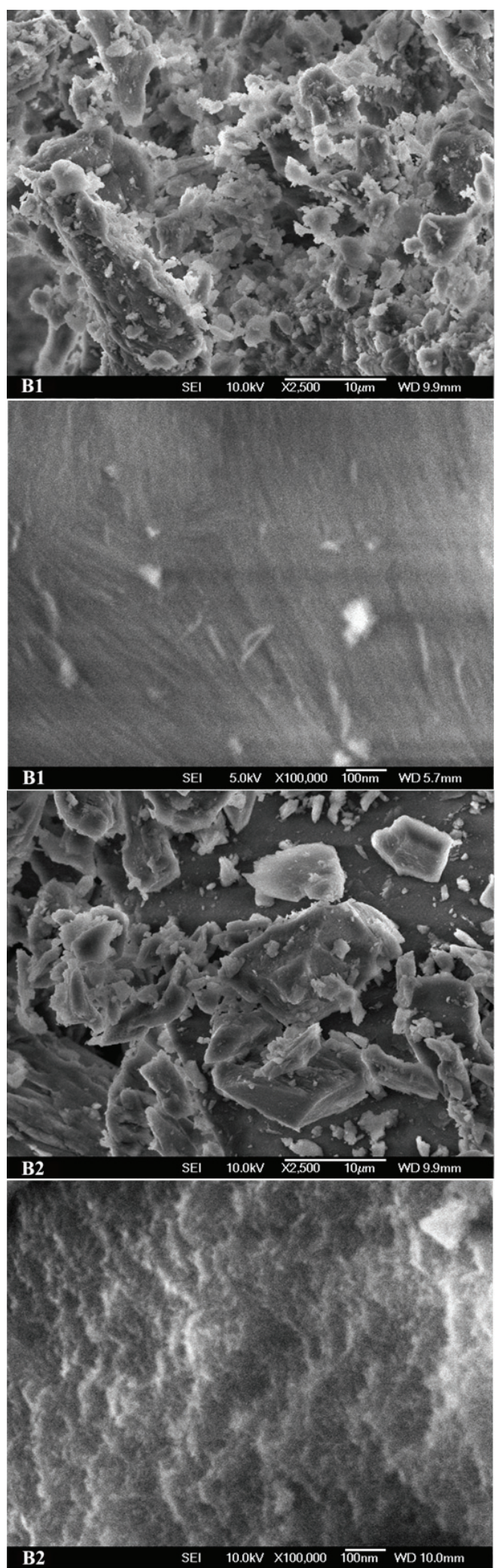

Figure 2. FE-SEM micrographs of samples B1 and B2 at magnification of 2500 and 100000 . very different shapes and sizes (Figure 2). Boehmite crystallites appear to be very small (few nanometers).

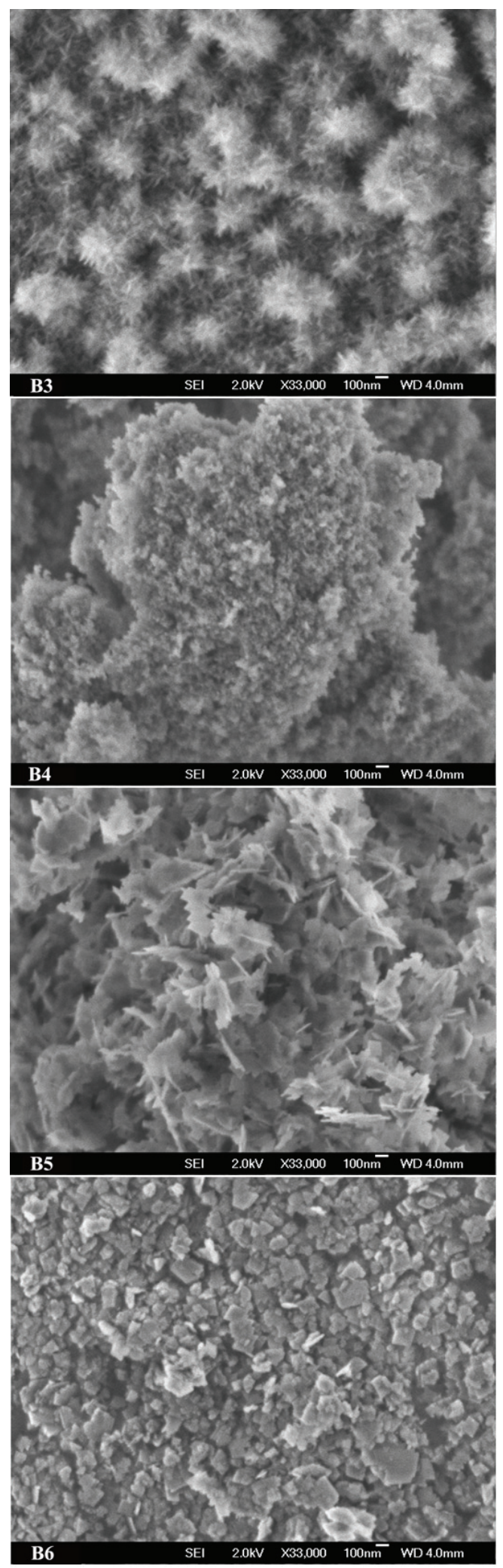

Figure 3. FE-SEM micrographs of samples B3, B4, B5, and B6 at magnification of $33000 \times$. 
High magnification (100,000 times) of sample B1 indicates the presence of scratches or channels on the sur-
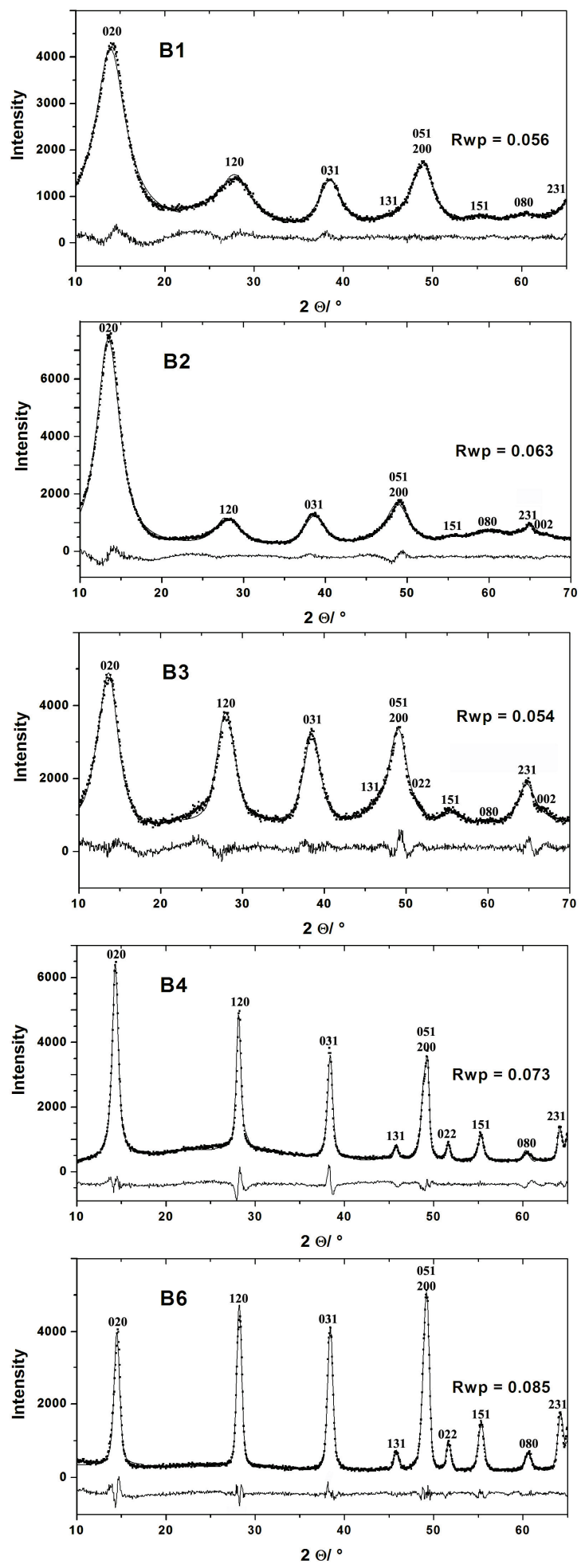

Figure 4. The results of Le Bail refinements (GSAS program) of powder diffraction patterns of samples B1, B2, B3, B4 and B6. Observed data are shown by squares, the calculated one by full line. Differences between the observed and calculated intensities are plotted in the same scale below each pattern. face of the grains. The presence of some very small (few nanometers) fiber-like particles indicates the anisotropic growth of boehmite crystallites. In case of sample B2, even at very high magnification individual boehmite particles could not be clearly seen.

FE-SEM micrographs of samples B3 to B6 (Figure 3 ) indicate a significant difference in the morphology of obtained boehmite crystallites. In sample B3 (obtained at $\mathrm{pH} \approx 6.0$ ) the interconnection between needle-shape boehmite crystallites forms a three-dimensional star morphology. Sample B4 contains the agglomerates of small boehmite granules of almost spherical symmetry. Sample B5 contains soft agglomerates (low bulk density) of irregular plates, while sample B6 contains more compact agglomerates of regularly shaped plates (Figure 3 ).

The results of XRD analysis show that boehmite (ICDD PDF-2 card No. 21-1307) is the only crystal phase present in all prepared samples. Significant broadening of the boehmite diffraction lines was used for size-strain line broadening analysis (estimation of $D_{\mathrm{V}}$ and $e$ values).

Figure 4 shows the results of Le Bail ${ }^{15}$ wholepowder-pattern profile refinements. Small differences between the observed and calculated patterns and very low values of the $R_{\mathrm{wp}}$ index indicate a relatively good reliability of the extracted values. The obtained results indicate a very small contribution of the micro-strain parameters (the refined values of the profile parameters $U, Y$ and $Y$ e were nearly 0 ) to the broadening of the boehmite diffraction lines. The obtained results indicate that boehmite crystallites are generally larger with the increase of $\mathrm{pH}$, temperature or time of hydrothermal treatment. However, regardless of the difference in processing parameters, boehmite crystallites in all products are of nanometric size with a pronounced size anisotropy. $^{22,23}$ In all diffraction patterns the size contribution to the line broadening appeared to be anisotropic with a significantly smaller $D_{\mathrm{V}}$ value in the direction parallel to the broadening axis 010 than in the directions perpendicular to the broadening axis 010 (Table 2).

\section{CONCLUSION}

The results of XRD analysis show that, regardless of significant changes in the processing parameters $(\mathrm{pH}$, temperature, time of synthesis), rapid hydrolysis of aluminum sec-butoxide resulted in the formation of nanosize boehmites. The results of FE-SEM analysis indicate a significant difference in the morphology of obtained boehmites (plates, needles, granules). The sizes of boehmite crystallites increase with the increase in $\mathrm{pH}$, temperature or the duration of hydrothermal treatment. However, the results of line-broadening analysis of powder diffraction patterns (Le Bail method program GSAS) indicate that boehmite crystallites in all 
products are of nanometric size with a pronounced size anisotropy. $D_{\mathrm{V}}$ values of the obtained boehmite products appeared to be about two times smaller in the direction parallel to the axis 010 (around 1.5 to $7 \mathrm{~nm}$ ) than in the directions perpendicular to the axis 010 (around 3 to 16 $\mathrm{nm}$ ). In all cases the parameters that contribute to the strain-broadening of the diffraction lines decrease to nearly zero, which suggests that the obtained boehmites are almost strain-free.

\section{REFERENCES}

1. K. Wefers and C. Misra: Oxides and Hydroxides of Aluminium, Alcoa Technical Paper No. 19 (Revised), Alcoa Laboratories, 1987.

2. J. Bugosh, J. Phys. Chem. 65 (1961) 1789-1793.

3. H. K. Varma, T. V. Mani, A. D. Damodaran, K. G. Warrier, and U. Balachandran: J. Am. Ceram. Soc. 77 (1994) 1597-1600.

4. S. Musić, Đ. Dragčević, S. Popović, and A. Turković, Mater. Lett. 18 (1994) 309-312.

5. S. Musić, Đ. Dragčević, and S. Popović, Mater. Lett. 40 (1999) 269-274.

6. B. E. Yoldas, J. Appl. Chem. Biotechnol. 23 (1973) 803-809.

7. H. S. Santos, P. K. Kiyohara, and P. S. Santos, Ceramics Internat. 20 (1994) 175-181.

8. P. Alphonse and M. Courty, Thermochim. Acta 425 (2005) 75-89

9. P. A. Buining, C. Pathmamanoharan, J. B. H. Jansen, and H. N.
W. Lekkerkerker, J. Am. Ceram. Soc. 74 (1991) 1303-1307.

10. S. Musić, Đ. Dragčević, S. Popović, and N. Vdović, Mater. Chem. Phys. 59 (1999) 12-19.

11. S. Musić, Đ. Dragčević, S. Popović, and N. Vdović, Mater. Sci. Eng. B 52 (1998) 145-153.

12. R. T. Tettenhorst and D. A. Hofmann, Clays Clay Miner. 28 (1980) 373-380.

13. X. Bokhimi, J. A. Toledo-Antonio, M. L. Guzman-Castillo, and F. J. Hernandez-Beltran, Solid State Chem. 159 (2001) 32-40.

14. A. E. Gobichon, B. Rebours, and P. Euzen, Mater. Sci. Forum 378-381 (2001) 523-528.

15. A. Le Bail, H. Duroy, and J. L. Fourquet, Mater. Res. Bull. 23 (1988) 447-452.

16. A. C. Larson and R. B. Von Dreele, General Structure Analysis System GSAS, Los Alamos National Laboratory Report, 2001.

17. B. H. Toby, J. Appl. Crystallogr. 34 (2001) 210-213.

18. D. Balzar, N. Audebrand, M. Daymond, A. Fitch, A. Hewat, J. I. Langford, A. Le Bail, D. Louër, O. Masson, C. N. McCowan, N. C. Popa, P. W. Stephens, and B. Toby, J. Appl. Cryst. 37 (2004) 911-924.

19. P. Thompson, D. E. Cox, and J. B. Hastings, J. Appl. Crystal$\log r .20$ (1987) 79-83.

20. A. B. Kiss, G. Keresztury, and L. Farkas, Spectrochim. Acta Part A 36 (1980) 653-658.

21. K. Nakamoto (Ed.), Infrared and Raman Spectra of Inorganic and Coordination Compounds, 5th ed. New York, John Wiley \& Sons Inc., 1997.

22. N. C. Popa and D. Balzar, J. Appl. Crystallogr. 41 (2008) 615-627.

23. B. Antić, A. Kremenović, A. S. Nikolić, M. Stoiljković, J. Phys. Chem. B 108 (2004) 12646-12651. 